\title{
Article
}

\section{The Role of Peripheral Nerve Electrotherapy in Functional Recovery of Muscle Motor Units in Patients after Incomplete Spinal Cord Injury}

\author{
Juliusz Huber ${ }^{1, *} \mathbb{1}$, Katarzyna Leszczyńska ${ }^{1}$, Agnieszka Wincek ${ }^{1}$, Agnieszka Szymankiewicz-Szukała ${ }^{1}$, \\ Wojciech Fortuna ${ }^{2,3}$, Stefan Okurowski ${ }^{4}$ and Paweł Tabakow ${ }^{2}$ \\ 1 Department of Pathophysiology of Locomotor Organs, Poznan University of Medical Sciences, 28 Czerwca \\ 1956 nr 135/147, 60-545 Poznań, Poland; kat.leszczynska@gmail.com (K.L.); awincek@ump.edu.pl (A.W.); \\ aszymankiewicz@ump.edu.pl (A.S.-S.) \\ 2 Department of Neurosurgery, Wroclaw Medical University, Borowska 213, 50-556 Wroclaw, Poland; \\ wfortuna@onet.pl (W.F.); p.tabakov@wp.pl (P.T.) \\ 3 Bacteriophage Laboratory, Ludwik Hirszfeld Institute of Immunology and Experimental Therapy, Polish \\ Academy of Sciences, Rudolf Weigl 12, 53-114 Wrocław, Poland \\ 4 Neurorehabilitation Center for Treatment of Spinal Cord Injuries AKSON, Bierutowska 23, \\ 51-317 Wrocław, Poland; sokurowski@wp.pl \\ * Correspondence: juliusz.huber@ump.edu.pl; Tel.: +48-504041843
}

check for

updates

Citation: Huber, J.; Leszczyńska, K.; Wincek, A.; Szymankiewicz-Szukała, A.; Fortuna, W.; Okurowski, S.;

Tabakow, P. The Role of Peripheral Nerve Electrotherapy in Functional Recovery of Muscle Motor Units in Patients after Incomplete Spinal Cord Injury. Appl. Sci. 2021, 11, 9764. https://doi.org/10.3390/app11209764

Academic Editor: Giuliana Muzio

Received: 25 July 2021

Accepted: 15 October 2021

Published: 19 October 202

Publisher's Note: MDPI stays neutral with regard to jurisdictional claims in published maps and institutional affiliations.

Copyright: (c) 2021 by the authors. Licensee MDPI, Basel, Switzerland. This article is an open access article distributed under the terms and conditions of the Creative Commons Attribution (CC BY) license (https:/ / creativecommons.org/licenses/by/ $4.0 /)$.

\begin{abstract}
Functional electrical nerve stimulation (FES) is a non-invasive technique for neuromodulation and may have the potential for motor rehabilitation following incomplete spinal cord injury (iSCI). Axonal degeneration in motor fibers of lower extremity nerves is an inevitable secondary pathological change in iSCI subjects, despite no direct damage to lumbosacral neuromeres. This study evaluated the role of FES with individual parameters based on results of comparative neurophysiological studies. Forty-two participants with C4 to Th12 iSCI received repetitive sessions of electrostimulations applied to peroneal and tibial motor fibers, performed five times a week from 6 to 14 months, and the uniform system of kinesiotherapeutic treatment. The average duration of one electrostimulation session was $17 \mathrm{~min}$, stimulation frequency of a train $20-70 \mathrm{~Hz}$, duration of 2-3 s, intervals $2-3 \mathrm{~s}$, pulses intensity 18-45 mA. The algorithm change was based on objective tests of subsequent surface electromyography (sEMG), and electroneurography (ENG) recordings. The same neurophysiological studies were also performed in patients after C2-Th12 iSCI treated with kinesiotherapy only (K group, $N=25$ ) and compared with patients treated with both kinesiotherapy and electrostimulation $(\mathrm{K}+\mathrm{E}, \mathrm{N}=42)$. The study revealed improvements in sEMG parameters recorded from tibialis anterior, gastrocnemius, extensor digitorum brevis muscles, and ENG evoked a compound muscle action potential recorded following bilateral stimulation of more peroneal than tibial nerves. Neurophysiological recordings had significantly better parameters in the K + E group of patients after therapy but not in the K group patients. The improvement of the motor transmission peripherally may reflect the specific neuromodulatory effect of FES algorithm evaluated with sEMG and ENG. FES may inhibit degeneration of axons and support functional recovery after iSCI.
\end{abstract}

Keywords: incomplete spinal cord injury; nerve electrostimulation; electromyography; electroneurography

\section{Introduction}

There has been no doubt that the injured spinal cord is capable of spontaneous regeneration for almost two decades. Evidence-based methods of rehabilitation (kinesioand physicotherapy) that support functional recovery are promising for patients with incomplete spinal cord injury (iSCI) to recover sensory and motor neural transmission and improve their quality of life [1]. Research on this topic mainly focuses on the modern methods of the brain supraspinal centers stimulation, which intends to enhance the 
transmission of efferent neural impulses within the injured spinal pathways [2]. However, after iSCI, the secondary changes in the fibers of lower extremities nerves occur, which may be caused by the disturbances of efferent impulses transmission from the supraspinal centers to motor cells below the damage level $[3,4]$. Several studies also revealed that despite no structural cause of damage at the lower spinal levels, degeneration in motor units might appear [5]. Thus, iSCI patients' treatment should include not only the surgical spine stabilization and continuous, intensive kinesiotherapy, but also the methods that prevent the secondary degenerative changes in nerve fibers [6]. Electrostimulation may be such a treatment, preferably of nerves rather than muscles, and the strategy should rely on personally adjusted parameters of impulses based on the current state of the neural transmission. This type of electrotherapy may be personalized, safe, and controlled in use, and it may give better, and long-lasting functional effects than the previously proposed algorithms. This therapy's main aim in iSCI patients should be protection and the inhibition of inevitable atrophic changes in nerves and muscles because it generates the spread of neural impulses in orthodromic and antidromic directions. It can be hypothesized that standard algorithms used in contemporary electrostimulation procedures sometimes lead to iatrogenic damage, or they may not bring the expected therapeutic effects [6]. Moreover, it can be assumed that electrostimulation of nerves is a safe technique with therapeutic potential for motor function rehabilitation following iSCI when parameters are adjusted to the current functional state of neural transmission in nerves and activity in muscle motor units in a treated patient; it is necessary to understand how this therapy can be optimized in the clinical practice. The expected changes in motor fibers during degenerative processes in iSCI patients may be of an axonal and later demyelinating type $[5,7,8]$. The quality of electrostimulation algorithms used for treatment of iSCI patients may be effectively improved by neurophysiological evaluation that consists of electroneurography (ENG), and surface electromyography (sEMG) recordings. These objective, non-invasive tests assess abnormalities in the transmission of neural impulses and preserved the activity of neuromuscular synapses, respectively.

Effects of electrostimulation treatment in iSCI patients are mostly case presentations or evidence of a weak efficiency in motor function rehabilitation following applied kinesiotherapy and physical therapy procedures in a limited number of subjects. Several studies have also analyzed the improvement of neural signal transmission in injured fibers $[6,9,10]$. Positive effects of electrical stimulation of the motor cortex, spinal cord, or peripheral nerves, which modulate lumbar spinal cord excitability, are mainly presented in experimental studies on animals, and rarely in human trials [11,12]. Studies on humans do not present electrotherapy algorithms based on physiological premises or parameters referred to as high-frequency (or low combined with high-frequency) and high-strength stimulation. Moreover, more ultra-structural trials than measurable clinical outcomes have proved their efficiency in both studies investigating structural damage to efferent axons and studies exploring abnormalities in preserved motor axons [10,13-15]. Only a few studies have utilized sEMG for the outcome presentation [16].

In our previous study, a trial with positive effects on motor function rehabilitation of individualized electrotherapy procedures in subjects after stroke was presented [17]. This comparative study evaluates the role of individually adjusted nerve electrostimulations in the functional recovery of muscle motor units in iSCI patients according to their current neurophysiological health status. The algorithm utilizes the results of precise, sensor-based, non-invasive neurophysiological sEMG and ENG tests. Its effectiveness has been verified by a comparison of the results recorded in patients treated with electrostimulation and kinesiotherapy versus kinesiotherapy only. We hypothesize that our protocol of stimulation of the peroneal and tibialis posterior nerves may decrease axonal loss due to lumbar lower motor neuron degeneration. 


\section{Materials and Methods}

\subsection{Participants}

We preliminarily recruited a total number of 84 subjects after iSCI and 42 healthy volunteers. Figure 1 summarizes patient enrolment, participation, and attrition during the study period. All patients underwent neurosurgeries to stabilize the spine. The most common iSCI etiologies were vehicle accidents, industrial accidents, sports injuries, or physical assault. The main inclusion criteria were preservation of $1 / 3-1 / 4$ spinal structures within fibers and neurons in the white and grey matter at C2-Th12 levels, verified by MRI studies, which confirmed iSCI not less than four months but not more than one year from a spine injury (7.4 months on average), an agreement for participation in the project for not less than six months (Table 1). The main contraindications for the study were severe head injuries, episodes of epilepsy and other consequences of direct craniocerebral trauma, severe disorders of the cardiovascular system, pregnancy, electronic implants such as pacemakers and cochlear implants, stroke, plexopathies episodes in treatment, inflammatory diseases, and myelopathies before the incident.

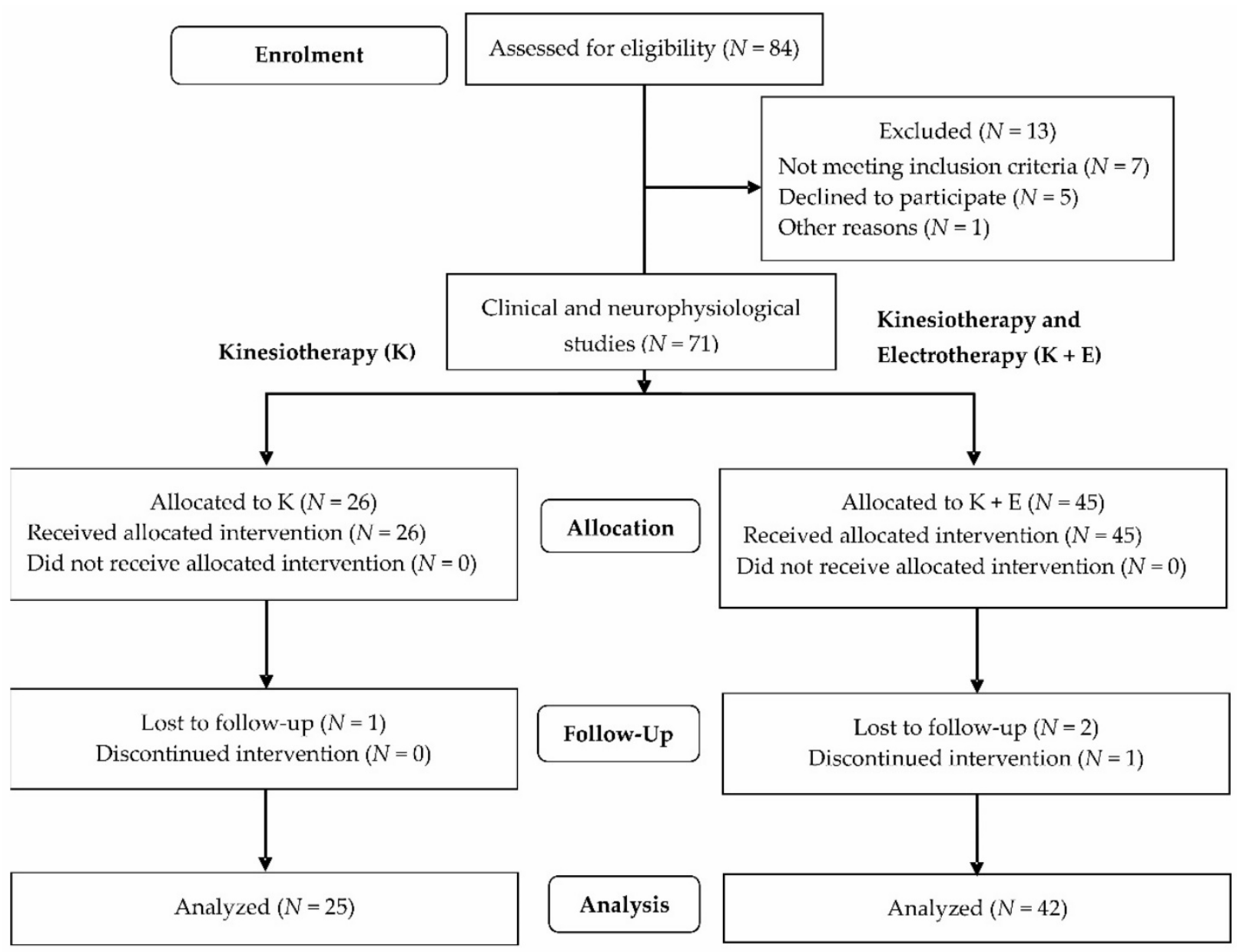

Figure 1. Flow chart of the study.

During enrolment, thirteen subjects were excluded from the sample (five declined to participate due to social reasons; seven did not meet the inclusion criteria; one showed a worsening health status). The patients were informed and understood the potential for no benefit and the risk of all procedures. Before the clinical and neurophysiological studies, all seventy-one included patients declared a stable psychological and social status. Clinical studies are a part of the American Spinal Injury Association (ASIA) impairment scale, and the tests revealed C or D (C stands for incomplete motor impairment, motor 
function is preserved below the level of injury, and more than half of the muscles tested below the level of injury have a muscle grade less than 3; D stands for incomplete motor impairment, motor function is preserved below the level of injury and at least half of the key muscles below the neurological level have a muscle grade of 3 or more). Forty-five patients who agreed to participate in the project with electrotherapy of nerves and who did not present contraindications for electrostimulation procedures were recruited to $\mathrm{K}+\mathrm{E}$ group (treated with kinesiotherapy and electrotherapy). The other twenty-five patients received only kinesiotherapeutic treatment with the same program as the $\mathrm{K}+\mathrm{E}$ group. One patient discontinued intervention, three patients were lost to follow-up, and, finally, the analyzed groups were as follows: $\mathrm{K}-25$ patients, and $\mathrm{K}+\mathrm{E}-42$ patients. $\mathrm{K}+\mathrm{E}$ group patients represented ASIA C -39 patients, and $\mathrm{D}-3$ patients; in the K group there were $\mathrm{C}-19$ patients, and $\mathrm{D}-6$ patients.

Table 1 presents the anthropometric characteristics and the spinal injury levels of the patients in the two studied groups. The same set of clinical and neurophysiological studies was applied to the group of 42 healthy volunteers (control group) to obtain reference values. Patients were studied twice (T0-before treatment, $\mathrm{T} 1$ - after treatment) to compare changes in electrophysiological parameters at two stages of observation and to analyze how kinesiotherapy combined with electrotherapy or kinesiotherapy as a single method of treatment influenced their health status. The age of the healthy group was $35.7 \pm 5.2$ (range from 26 to 45), and their height $163-179 \mathrm{~cm}$ with a mean of $173.3 \pm 5.9 \mathrm{~cm}$. The two groups of patients and healthy volunteers did not differ significantly in age, height, and weight. The patients of the group K and K + E were similarly observed for about 10-11 months on average and were approximately 7.3 months after the injury on average. The study was conducted according to the guidelines of the Declaration of Helsinki and approved by the Bioethics Committee of the University of Medical Sciences (Decision No. 559/2018).

Table 1. Characteristics of the subjects studied in two groups.

\begin{tabular}{|c|c|c|c|c|}
\hline \multirow[b]{2}{*}{ Variable } & \multicolumn{2}{|c|}{$K+$ E Group $(N=42)$} & \multicolumn{2}{|c|}{ K Group $(N=25)$} \\
\hline & Mean \pm SD & Min-Max & Mean \pm SD & Min-Max \\
\hline Age & $36.6 \pm 5.3$ & $26-49$ & $37.2 \pm 4.1$ & $25-48$ \\
\hline Height (cm) & $174.0 \pm 4.7$ & $162-183$ & $175.5 \pm 4.9$ & 158-181 \\
\hline Weight (kg) & $74.9 \pm 8.7$ & $53-81$ & $72.3 \pm 6.5$ & $52-84$ \\
\hline Spine injury & \multicolumn{2}{|c|}{ C4-Th12 } & \multicolumn{2}{|c|}{ C2-Th12 } \\
\hline Time from spine injury (months) & $7.2 \pm 2.7$ & $4-12$ & $7.5 \pm 1.3$ & $5-13$ \\
\hline Observation time (months) & $10.3 \pm 1.6$ & $6-14$ & $11.2 \pm 1.1$ & $6-17$ \\
\hline Expected stimulation (hours) & $153.6 \pm 25.5$ & $60-210$ & NA & NA \\
\hline Detected stimulation (hours) & $144.2 \pm 25.4$ & 67-198 & NA & NA \\
\hline Train stimulation frequency $(\mathrm{Hz})$ & $39.0 \pm 11.0$ & $20-70$ & NA & NA \\
\hline Single stimulus duration (ms) & $17.5 \pm 2.59$ & $11-22$ & NA & NA \\
\hline Train duration (s) & $2.6 \pm 0.5$ & $2-3$ & NA & NA \\
\hline Interval between trains (s) & $2.5 \pm 0.5$ & $2-3$ & NA & NA \\
\hline Session duration (minutes) & $17.0 \pm 2.3$ & $15-20$ & NA & NA \\
\hline Applied stimulus strength (mA) R & $28.9 \pm 6.3$ & $18-45$ & NA & NA \\
\hline Applied stimulus strength (mA) L & $28.8 \pm 6.2$ & $18-42$ & NA & NA \\
\hline
\end{tabular}

E—electrotherapy, K—-kinesiotherapy, R—right side, L—left side, NA—not applicable.

\subsection{Procedures and Intervention}

\subsubsection{Kinesiotherapy}

Patients treated with kinesiotherapy aimed to improve motor and sensory functions by the application of exercises supervised by a physiotherapist. The kinesiotherapy program was performed at the Neurorehabilitation Center for Treatment of Spinal Cord Injuries (AKSON, Wroclaw, Poland) with a similar, uniform methodology. Patients were treated $4-5 \mathrm{~h}$ per day, five days a week, under physiotherapists' supervision. Daily training included a range of motion and stretching exercises with loadings for $1 \mathrm{~h}$ (the minimal increase was $100 \mathrm{~g}$ ), adjusted individually for certain groups of partially paralyzed muscles 
showing the activation improvement. A verticulator was used depending on the spasticity or hypotonia. Minor neurological symptoms, such as tingling or a decrease in muscle strength or function of the autonomic nervous system, determined the verticalization bed usage. Locomotor training on a treadmill with a handrail, and later without any support, lasted approximately $3 \mathrm{~h}$ a week. Sensory training of posture and balance on a specially designed vibration platform was performed for $1 \mathrm{~h}$. The number of repetitions in one cycle ranged from 6 to 15, depending on the patient's condition, five days per week. The stretching exercises were performed in two sessions lasting $3 \mathrm{~h}$ each. Spasticity or hypertonia level determined the magnitude of loading exercises. The principles of uniform kinesiotherapy treatment have been described elsewhere [18].

\subsubsection{Neurophysiological Studies}

All subjects underwent neurophysiological tests twice to evaluate motor unit activity in calf muscles and transmission of impulses in the motor fibers of the lower extremities (Figure 2). The tests were performed before and after nerve electrostimulation procedures and lasted about 6-17 months (Table 1). The electrostimulation algorithm was personally adjusted based on the results of sEMG and ENG recordings conducted prior to the treatment.
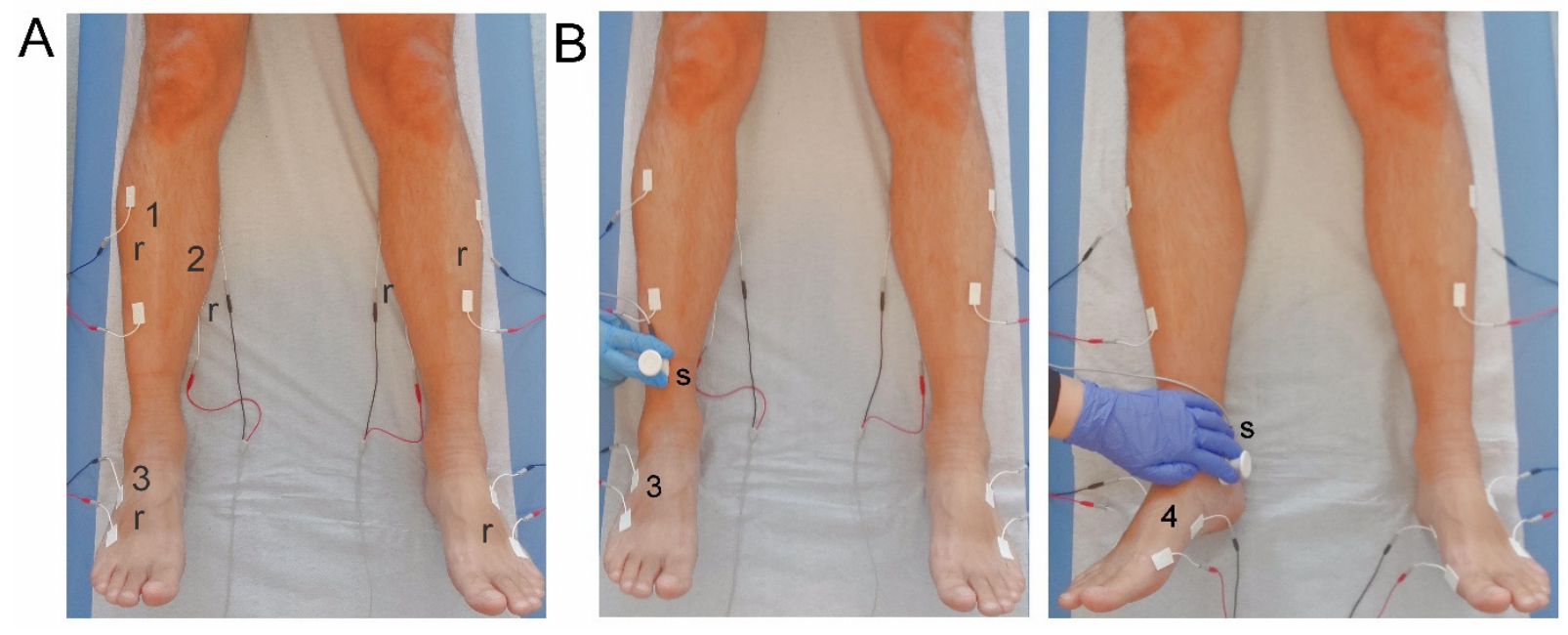

Figure 2. Photographs showing principles of neurophysiological studies in healthy volunteers and iSCI patients. (A) Distribution of surface electrodes in the anterior aspect of the human body for bilateral electromyographical recordings ( $\mathrm{r}$ ) from lower extremity muscles (1-tibialis anterior muscle, 2-medial gastrocnemius muscle, 3-extensor digitorum brevis muscle). (B) Sites of bipolar stimulating electrode (s) application for electrical stimulation of peroneal (left side) and tibial (right side) nerves at the ankle during electroneuronographic recordings of evoked M-wave potentials from extensor digitorum brevis (3), and abductor hallucis longus (4) muscles.

The sEMG and ENG recordings were performed using the KeyPoint Diagnostic System (Medtronic A/S, Skovlunde, Denmark) in an air-conditioned room with an average temperature of $22{ }^{\circ} \mathrm{C}$, with the patient in a supine position.

The sEMG activity was recorded from the bilateral tibialis anterior (TA), gastrocnemius (GS), and extensor digititorum brevis muscles (EX) with surface electrodes during their maximal contraction attempts lasting $5 \mathrm{~s}$ (Figure 2A). Standard disposable $\mathrm{Ag} / \mathrm{AgCl}$ surface electrodes with an active surface of $5 \mathrm{~mm} 2$ were used. The ground electrode was located on the distal part of the leg. The upper $10 \mathrm{kHz}$ and lower $20 \mathrm{~Hz}$ filters of the recorder were used. In the first stage of the trial, the patient was asked to fully relax the examined muscles and then perform a maximal contraction for $5 \mathrm{~s}$ during which the simultaneous recording took place. Participants were instructed to contract the tested muscle as hard and as quickly as possible until the neurophysiologist requested them to finish the attempt. The test was conducted three times, with a one-minute interval resting period between each 
muscle contraction; the recording with the highest amplitude (in $\mu \mathrm{V}$ ) and frequency (in $\mathrm{Hz}$ ) parameters was selected for analysis. The average amplitude parameters (minimummaximum, peak-to-peak, recruiting motor unit action potential deflections with reference to the isoelectric line measured in $\mu \mathrm{V}$ ) and motor unit firing frequencies (number of recruited motor unit action potentials in $\mathrm{Hz}$ ) were analyzed in recordings. The frequency index from 5 to $1(5,>95 \mathrm{~Hz}$, considered as myogenic; $4,95-70 \mathrm{~Hz}$, considered normal; 3, $65-40 \mathrm{~Hz}$, considered moderate neurogenic; $2,35-10 \mathrm{~Hz}$, considered severe neurogenic; $1,<10 \mathrm{~Hz}$, considered as rudimentary) was used according to the description used elsewhere, with the use of automatic analyzing software included in the KeyPoint System, compared with the online readings of sEMG recordings [19]. sEMG recordings were performed at the base time of $80 \mathrm{~ms} / \mathrm{D}$ and amplification of 20-1000 $\mu \mathrm{V}$. They were recorded with an active electrode placed on the muscle belly and a reference electrode on its distal tendon according to the Guidelines of the European Federation of Clinical Neurophysiology.

ENG examinations of motor fiber transmission within peroneal and tibial nerves were performed (CMAP, $\mathrm{M}$ waves recordings) (Figure 2B). Nerves were stimulated with electrical pulses (rectangular, $0.2 \mathrm{~ms}$ duration, at $1 \mathrm{~Hz}$, the intensity from $0-80 \mathrm{~mA}$ ) bilaterally; evoked potentials were recorded from TA and EX muscles with surface electrodes. The parameters of amplitude (in $\mu \mathrm{V}$ ) and latency (in ms) were analyzed in M-wave ENG recordings based on the methodology described elsewhere $[8,9,18]$. ENG recordings were collected at the amplification of 100-5000 $(\mu \mathrm{V})$ and a time base of $8 \mathrm{~ms}$. All tests were repeated twice before (T0) and after (T1) therapy, and parameters of sEMG and ENG were compared to normative values recorded in healthy volunteers with similar anthropometric properties (Table 2).

\subsubsection{Nerve Electrotherapy}

The main form of physical therapy applied to iSCI patients from the $\mathrm{K}+\mathrm{E}$ group was nerve electrostimulation procedures. Patients did not receive repetitive transcranial magnetic stimulation or other electrostimulation methods and did not have electrostimulation towards urinary dysfunctions during the whole observation period. A personal, mobile, four-channel stimulator (NeuroTrac ${ }^{\circledR S}$ Sports XL, Verity Medical Ltd., UK) was used for electrostimulation (Figure 3A). The device was equipped with an algorithm of stimulation parameters individually adjusted for a patient, based on sEMG and ENG evaluation performed in T0. In addition, the device also had the option to read out from memory data on the frequency and regularity of the patient's stimulation, which is valuable information for treatment verification (Table 1). The therapist could also set parameter, save, and secure the setting to prevent unplanned changes performed by participants. This had a significant impact on the behavior of the patient, who, while being under control, more carefully followed the stimulation regime. Two pairs of self-adhesive surface electrodes (Axelgaard Ultrastim Wire Neurostimulation Electrodes with MultiStick Gel, $5 \mathrm{~cm} \times 5 \mathrm{~cm}$, Axelgaard Manufacturing Co. Ltd., Denmark, Møgelhøj 2, 8520 Lystrup) were placed over the anatomical passage of peroneal and tibial nerves bilaterally at the knee to perform the electrostimulations in an alternative mode (Figure 3A). The anode was placed proximally to the cathode. 

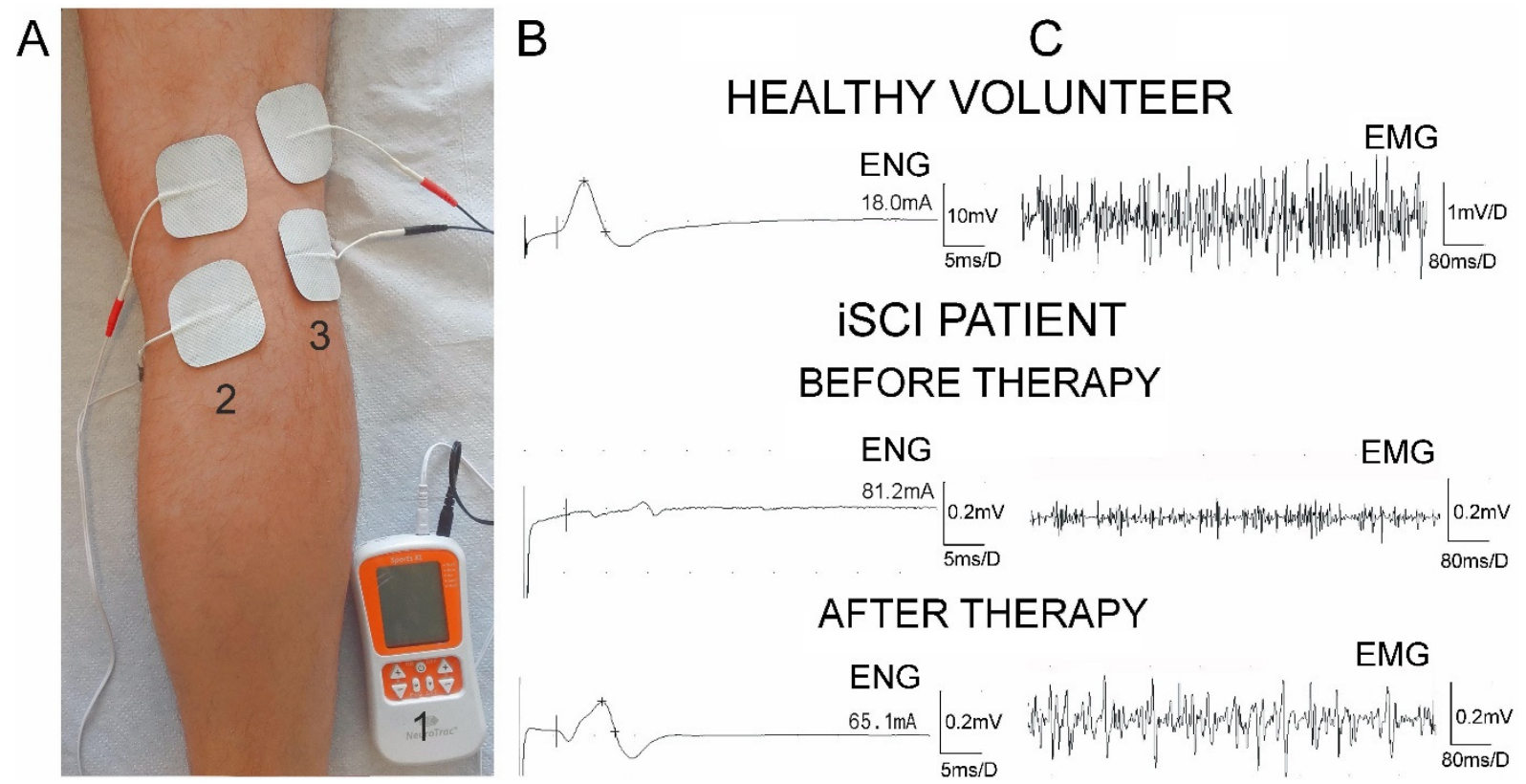

Figure 3. (A) Photograph of the device (1) for tibial (2), and peroneal (3) nerve electrostimulation with the presentation of the position of stimulating electrodes along the anatomical passage of popliteal fossa, and laterally to the head of the fibula, respectively. (B) Examples of M-wave-evoked potential recordings following electrical stimulation of peroneal nerves during electroneurographic studies. (C) Examples of electromyographical recordings from tibialis anterior muscles. The comparisons of neurophysiological recordings from a healthy volunteer and one of the patients with iSCI before and after therapy are presented.

The stimulation algorithm included the duration of one stimulation session (at least once a day) for 15-20 $\mathrm{min}$ (17 $\mathrm{min}$ on average), depending on the severity of the changes in nerve impulse minutes transmission within motor fibers of lower extremity nerves determined in ENG tests, and the results of the sEMG frequency parameter recorded during the maximal muscle contraction attempt $(20-70 \mathrm{~Hz}, 39 \mathrm{~Hz}$ on average; Table 1). The frequency of bipolar rectangular electric pulses applied in series also depended on the sEMG recorded recruitment of muscle motor units during attempts of three maximal contractions. Short bursts called pulsons, optimizing stimulation in terms of charge required to reach threshold and selectivity of stimulated fibers, were introduced as a novel electrostimulation procedure according to the suggestions of Günter et al. [6].

The single stimulus duration was calculated from the repetitive measurements of successive single muscle motor action potentials in sEMG recordings (17.5 ms on average; Table 1). In general, patients with moderate neurogenic changes received stimuli with a duration of 11 to $17 \mathrm{~ms}$, and those with severe neurogenic changes a duration of 18 to $22 \mathrm{~ms}$. Patients who represented severe neurogenic changes received stimulations with frequencies from 20 to no more than $30 \mathrm{~Hz}$, and those with moderate neurogenic changes from 40 to $70 \mathrm{~Hz}$. The sessions were performed five times a week for not less than 6 months and a maximum of 14 months (10.2 months on average). Intervals of 2-3 s between pulse series ( $2.5 \mathrm{~s}$ on average), training duration of $2-3 \mathrm{~s}$ ( $2.6 \mathrm{~s}$ on average), and stimulus intensity from 18 to $45 \mathrm{~mA}$ ( $28.9 \mathrm{~mA}$ on average) for both sides were set. The stimulus strength was the only parameter adjusted by the patients. All participants were instructed to increase the stimulus strength and reach its maximal value when the toe's visible movement was observed without intrusive pain.

\subsection{Data Analysis}

Data were analyzed with Statistica, version 13.1 (StatSoft, Kraków, Poland). Descriptive statistics included mean values, standard deviations (SD), and minimum (min) and maximum $(\max )$ values for measurable variables. Minimum, maximum, and median 
values were used for the description of ordinal scale variables. The normality distribution and homogeneity of variances were conducted mostly with Shapiro-Wilk tests and with Leven's tests in some cases. In 42 patients of both groups (K+E, K) with incomplete spinal cord injuries at the cervical and thoracic levels, the mean values of parameters from sEMG and ENG tests were compared using Student's t-test, Welch test, Mann-Whitney test or Wilcoxon test. It was assumed that a comparison of values at $p \leq 0.05$ determined significantly statistical differences. Before the study was completed, the preliminary statistical analysis determined the required sample size using the primary outcome variable sEMG recordings from extensor digitorum brevis muscles before and after treatment with a power of $80 \%$ and a significance level of 0.05 (two-tailed). The mean and standard deviation (SD) were calculated using the data from the first ten subjects. The sample size software estimated that at least 30 subjects were needed.

\section{Results}

None of the participants reported side effects or pain during the treatment sessions, and none of them reported persistent pain after the therapy had finished. The expected duration of the whole therapy cycle was $153 \mathrm{~h}$, while the detected duration recorded from the data readings of stimulator memory in T1 was $144 \mathrm{~h}$. Therefore, it could be concluded that most of the patients maintained the therapy regime (Table 1 ). The proportional decrease in the stimulus strength in milliamps ( $28 \mathrm{~mA}$ on average) was found in T1. The value of the rectangular stimulus duration that needed to be adjusted for patients, based on the results of single motor unit action potential recordings in sEMG studies, was $17.5 \mathrm{~ms}$ on average, which is characteristic of the neurogenic type of muscle motor unit injury.

The data in Table 2 indicate that the parameters of amplitude more than frequency index of sEMG recordings from all muscles on both sides differed significantly at $p<0.001$ compared to those recorded in the healthy volunteers, both in T0 as well as in T1. However, the data also indicate a significant improvement of the above parameters in T0 versus $\mathrm{T} 1$ in iSCI subjects from the $\mathrm{K}+\mathrm{E}$ group. The examples of recordings from one of the iSCI patients (Figure $3 \mathrm{C}$ ) showed that before the application of individually selected parameters of electrostimulation to lower extremities nerves, the sEMG amplitudes and frequencies of motor unit action potential requirements recorded from the TA were lower and then increased following the application of personalized electrotherapy. 


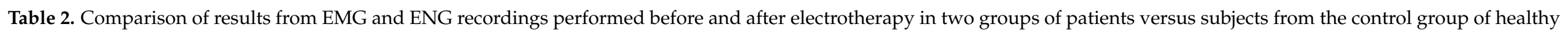
volunteers.

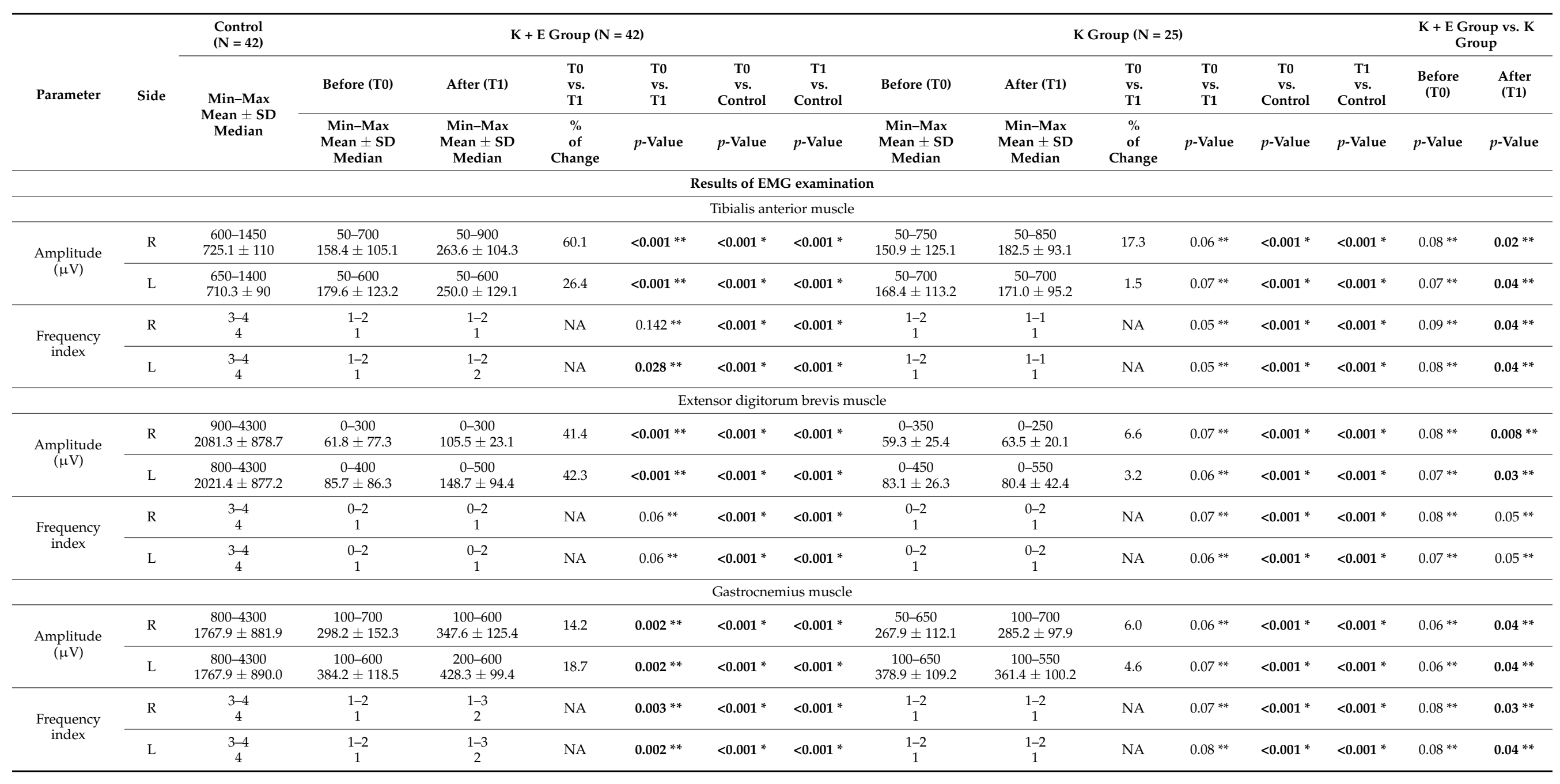


Table 2. Cont.

\begin{tabular}{|c|c|c|c|c|c|c|c|c|c|c|c|c|c|c|c|c|}
\hline \multirow[b]{2}{*}{ Parameter } & \multirow[b]{2}{*}{ Side } & \multirow{2}{*}{$\begin{array}{c}\text { Control } \\
(\mathrm{N}=42) \\
\\
\\
\text { Min-Max } \\
\text { Mean } \pm \text { SD } \\
\text { Median }\end{array}$} & \multicolumn{6}{|c|}{$\mathrm{K}+\mathrm{E}$ Group $(\mathrm{N}=42)$} & \multicolumn{6}{|c|}{ K Group $(N=25)$} & \multicolumn{2}{|c|}{$\begin{array}{c}\mathrm{K}+\mathrm{E} \text { Group vs. K } \\
\text { Group }\end{array}$} \\
\hline & & & Before (T0) & After (T1) & $\begin{array}{l}\text { T0 } \\
\text { vs. } \\
\text { T1 }\end{array}$ & $\begin{array}{l}\text { T0 } \\
\text { vs. } \\
\text { T1 }\end{array}$ & $\begin{array}{c}\text { T0 } \\
\text { vs. } \\
\text { Control }\end{array}$ & $\begin{array}{c}\text { T1 } \\
\text { vs. } \\
\text { Control }\end{array}$ & Before (T0) & After (T1) & $\begin{array}{l}\text { T0 } \\
\text { vs. } \\
\text { T1 }\end{array}$ & $\begin{array}{l}\text { T0 } \\
\text { vs. } \\
\text { T1 }\end{array}$ & $\begin{array}{c}\text { T0 } \\
\text { vs. } \\
\text { Control }\end{array}$ & $\begin{array}{c}\text { T1 } \\
\text { vs. } \\
\text { Control }\end{array}$ & $\begin{array}{l}\text { Before } \\
\text { (T0) }\end{array}$ & $\begin{array}{l}\text { After } \\
\text { (T1) }\end{array}$ \\
\hline \multicolumn{17}{|c|}{ Results of ENG examination } \\
\hline \multicolumn{17}{|c|}{ Peroneal nerve } \\
\hline$\underset{(\mu \mathrm{V})}{\text { Amplitude }}$ & $\mathrm{L}$ & $\begin{array}{c}3500-13,000 \\
8469.0 \pm 2488.8\end{array}$ & $\begin{array}{c}50-1600 \\
369.8 \pm 347.3\end{array}$ & $\begin{array}{c}200-1800 \\
583.3 \pm 359.4\end{array}$ & 36.6 & $<0.001^{\mathrm{a}}$ & $<0.001 *$ & $<0.001 *$ & $\begin{array}{c}50-1500 \\
352.6 \pm 242.1\end{array}$ & $\begin{array}{c}100-1700 \\
399.7 \pm 129.1\end{array}$ & 11.7 & $<0.001^{a}$ & $<0.001 *$ & $<0.001 *$ & $0.05^{* *}$ & $0.04 * *$ \\
\hline \multirow{2}{*}{$\begin{array}{l}\text { Latency } \\
\quad(\mathrm{ms})\end{array}$} & $\mathrm{R}$ & $\begin{array}{c}3.1-4.9 \\
4.2 \pm 0.4 \\
\end{array}$ & $\begin{array}{c}3.7-7.1 \\
5.1 \pm 0.4\end{array}$ & $\begin{array}{c}2.5-6.8 \\
4.1 \pm 0.2 \\
\end{array}$ & 19.6 & $<0.001 * *$ & $<0.001 *$ & $0.001 *$ & $\begin{array}{c}3.8-7.2 \\
5.3 \pm 0.2\end{array}$ & $\begin{array}{c}3.5-6.0 \\
5.7 \pm 0.1\end{array}$ & 7.0 & $0.05^{* *}$ & $<0.001 *$ & $0.001 *$ & $0.07^{* *}$ & $0.03 * *$ \\
\hline & $\mathrm{L}$ & $\begin{array}{c}3.5-5.2 \\
4.3 \pm 0.3 \\
\end{array}$ & $\begin{array}{c}3.7-8.0 \\
5.1 \pm 0.4 \\
\end{array}$ & $\begin{array}{c}3.5-6.6 \\
4.2 \pm 0.5 \\
\end{array}$ & 17.6 & $<0.001 * *$ & $<0.001 *$ & $0.001^{\mathrm{b}}$ & $\begin{array}{c}3.9-8.1 \\
5.0 \pm 0.6\end{array}$ & $\begin{array}{c}3.6-6.9 \\
5.3 \pm 0.3 \\
\end{array}$ & 5.6 & $0.06 * *$ & $<0.001 *$ & $0.001^{\mathrm{b}}$ & $0.08^{* *}$ & $0.03 * *$ \\
\hline \multirow{2}{*}{$\begin{array}{l}\text { Stimulus } \\
\text { strength }(\mathrm{mA})\end{array}$} & $\mathrm{R}$ & $\begin{array}{c}14-25 \\
18.9 \pm 3.0 \\
\end{array}$ & $\begin{array}{c}33-84 \\
58.8 \pm 13.7 \\
\end{array}$ & $\begin{array}{c}33-79 \\
48.1 \pm 10.2 \\
\end{array}$ & 18.1 & $<0.001 * *$ & $<0.001^{b}$ & $<0.001^{b}$ & $\begin{array}{c}32-90 \\
53.1 \pm 11.2 \\
\end{array}$ & $\begin{array}{c}31-91 \\
58.2 \pm 10.0 \\
\end{array}$ & 8.7 & $0.04^{* *}$ & $<0.001^{b}$ & $<0.001^{b}$ & $0.05^{* *}$ & $0.03 * *$ \\
\hline & $\mathrm{L}$ & $\begin{array}{c}12-25 \\
17.7 \pm 2.8 \\
\end{array}$ & $\begin{array}{c}35-85 \\
56.7 \pm 13.2 \\
\end{array}$ & $\begin{array}{c}35-71 \\
50.1 \pm 9.9 \\
\end{array}$ & 11.6 & $<0.001 * *$ & $<0.001^{\mathrm{b}}$ & $<0.001^{b}$ & $\begin{array}{c}36-84 \\
55.1 \pm 10.0\end{array}$ & $\begin{array}{c}34-79 \\
52.1 \pm 10.3 \\
\end{array}$ & 5.4 & $0.05^{* *}$ & $<0.001^{b}$ & $<0.001^{\mathrm{b}}$ & $0.08^{* *}$ & $0.08^{* *}$ \\
\hline \multicolumn{17}{|c|}{ Tibial nerve } \\
\hline \multirow{2}{*}{$\begin{array}{l}\text { Amplitude } \\
(\mu \mathrm{V})\end{array}$} & $\mathrm{R}$ & $\begin{array}{c}9000-4000 \\
1954.6 \pm 6876.8 \\
\end{array}$ & $\begin{array}{c}400-7500 \\
1524.2 \pm 1436.7 \\
\end{array}$ & $\begin{array}{c}500-8500 \\
1716.1 \pm 1125.1 \\
\end{array}$ & 6.6 & $<0.001 * *$ & $<0.001 *$ & $<0.001 *$ & $\begin{array}{c}350-7000 \\
1498.0 \pm 1225.6\end{array}$ & $\begin{array}{c}500-7500 \\
1321.9 \pm 1035.2 \\
\end{array}$ & 11.7 & $0.05^{* *}$ & $<0.001 *$ & $<0.001 *$ & $0.05^{* *}$ & $0.04 * *$ \\
\hline & $\mathrm{L}$ & $\begin{array}{c}1000-40,000 \\
2046.3 \pm 7395.1\end{array}$ & $\begin{array}{c}400-6000 \\
1568.0 \pm 1321.5\end{array}$ & $\begin{array}{c}500-7000 \\
1633.2 \pm 1430.4 \\
\end{array}$ & 3.9 & $0.015 * *$ & $<0.001 *$ & $<0.001 *$ & $\begin{array}{c}450-6500 \\
1521.4 \pm 1211.2\end{array}$ & $\begin{array}{c}500-7000 \\
1221.4 \pm 1100.1\end{array}$ & 19.7 & $0.02 * *$ & $<0.001 *$ & $<0.001 *$ & $0.07^{* *}$ & $0.03 * *$ \\
\hline \multirow{2}{*}{$\begin{array}{l}\text { Latency } \\
(\mathrm{ms})\end{array}$} & $\mathrm{R}$ & $\begin{array}{c}3.2-4.7 \\
4.1 \pm 0.4 \\
\end{array}$ & $\begin{array}{c}3.3-7.4 \\
4.7 \pm 0.9 \\
\end{array}$ & $\begin{array}{c}3.4-6.5 \\
4.6 \pm 0.8\end{array}$ & 2.1 & $0.029 * *$ & $0.002 *$ & $0.005 *$ & $\begin{array}{c}3.4-7.9 \\
4.6 \pm 0.5\end{array}$ & $\begin{array}{c}3.8-7.9 \\
4.8 \pm 0.3 \\
\end{array}$ & 4.1 & $0.06^{* *}$ & 0.003 * & 0.006 * & $0.06^{* *}$ & $0.05^{* *}$ \\
\hline & L & $\begin{array}{c}3.2-4.7 \\
4.1 \pm 0.4 \\
\end{array}$ & $\begin{array}{c}3.6-6.8 \\
4.8 \pm 0.8\end{array}$ & $\begin{array}{c}3.5-6.2 \\
4.6 \pm 0.7\end{array}$ & 2.1 & $<0.001^{\mathrm{a}}$ & $<0.001 *$ & $0.003 *$ & $\begin{array}{c}3.5-6.7 \\
4.7 \pm 0.2 \\
\end{array}$ & $\begin{array}{c}3.6-7.0 \\
4.7 \pm 0.5\end{array}$ & 0 & $<0.001^{a}$ & $<0.001$ * & $0.002 *$ & $0.05^{* *}$ & $0.06^{* *}$ \\
\hline \multirow{2}{*}{$\begin{array}{l}\text { Stimulus } \\
\text { strength }(\mathrm{mA})\end{array}$} & $\mathrm{R}$ & $\begin{array}{c}15-25 \\
20.2 \pm 3.0 \\
\end{array}$ & $\begin{array}{c}31-77 \\
53.6 \pm 11.2 \\
\end{array}$ & $\begin{array}{c}30-71 \\
52.0 \pm 10.2 \\
\end{array}$ & 2.9 & $<0.001^{\mathrm{a}}$ & $<0.001 *$ & $<0.001 *$ & $\begin{array}{c}30-92 \\
52.9 \pm 9.9 \\
\end{array}$ & $\begin{array}{c}31-78 \\
52.8 \pm 10.4\end{array}$ & 0 & $0.06^{\mathrm{a}}$ & $<0.001$ * & $<0.001 *$ & $0.07^{* *}$ & $0.07^{* *}$ \\
\hline & $\mathrm{L}$ & $\begin{array}{c}14-25 \\
18.8 \pm 3.1\end{array}$ & $\begin{array}{c}32-80 \\
54.3 \pm 11.7\end{array}$ & $\begin{array}{c}32-78 \\
51.5 \pm 10.5\end{array}$ & 5.1 & $<0.001^{\mathrm{a}}$ & $<0.001 *$ & $<0.001 *$ & $\begin{array}{c}33-82 \\
53.9 \pm 9.8\end{array}$ & $\begin{array}{c}34-79 \\
52.5 \pm 9.3\end{array}$ & 2.5 & $0.07^{a}$ & $<0.001 *$ & $<0.001 *$ & $0.06^{* *}$ & $0.05^{* *}$ \\
\hline
\end{tabular}

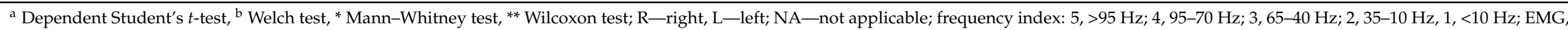

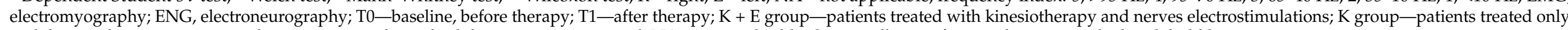

with kinesiotherapy; ranges, median, or mean and standard deviation are presented; NA-not applicable. Statistically significant values are marked with bold letters. 
The ENG data in Table 2 show that the amplitudes more than the latencies of M-wave recordings performed in iSCI patients differed at $p<0.001$ from normative parameters in T0 in both groups of patients. Stimuli strengths necessary to elicit compound muscle-evoked potentials were significantly higher in patients than in healthy volunteers at $55 \mathrm{~mA}$ on average. Applied electrotherapy treatment provided a significant increase in M-wave-evoked potential amplitude parameters and shortening of the latency value with a simultaneous decrease in stimulus strength necessary to evoke them in T1 (only in patients from the $\mathrm{K}+\mathrm{E}$ group), as can be seen from the examples of recordings in Figure $3 \mathrm{~B}$. All of the above axonal-type changes were more detectable and reversible following stimulations of peroneal than tibial nerves in both groups of patients.

The data in Table 2 indicate the higher percentage of improvement in parameters of sEMG recordings during maximal contraction in the $\mathrm{K}+\mathrm{E}$ group rather than in the $\mathrm{K}$ group. The neurophysiological parameters recorded in both groups of iSCI patients did not differ significantly before the therapy. However, they were significantly different in the final observation at $p$ from 0.05 to 0.008 .

\section{Discussion}

This study provides evidence of the positive effects of the application of functional electrical stimulation (FES) to nerves, with personalized and safe algorithm parameters based on the results of clinical neurophysiology tests in patients after iSCI. In general, the effect of peripheral axonal degeneration of motor fibers was significantly inhibited, which prevented degeneration of neuromuscular synapses at motor units of distal lower extremity muscles. Our findings also support the hypothesis that stimulation of peripheral nerves can modulate lumbar spinal cord excitability. The approach of stimulation of nerve fibers rather than muscle fibers seems to be more effective considering Hebb's theory of neuromodulation ("cells that fire together, wire together") [20]. Such stimulation evokes long-term effects on the spinal locomotor centers, creating central pattern generators and supporting motor recovery in iSCI patients [21]. Hebb's theory has been proven both in animal and human trials, which found that descending volleys and stimulation of afferent and efferent fibers peripherally induced the synaptic plasticity at the motor centers [22].

In our study, the stimulation of motor (in an orthodromic way) and sensory (in an antidromic way) nerve fibers was expected to evoke convergence and facilitation of sensory influences relayed from afferent fibers and increase the excitability of motoneurons transmitting impulses to effectors through a biofeedback mechanism. As a result, we recorded the increase in the amplitudes during sEMG recordings in T1, which expressed the improvement of muscle contractile properties in lower extremities; it possibly also correlated with the reinnervation of new muscles fibers. Moreover, the increase in the amplitude parameters in ENG recordings after stimulation of more peroneal than tibial nerves reflected the improvement of the transmission of the neural impulses.

Many investigators have reported the beneficial effects of nerve stimulations in iSCI patients. However, in these studies, the best approach, timing, duration, and intensity of electrotherapy parameters were not sufficiently described to repeat the tests. Electrostimulation protocols were not systematically documented, which limits meta-analyses and makes it impossible to replicate therapies with similar procedures [13]. Research that provided valuable evidence of the effectiveness of electrostimulation after injuries in animal trials [13,16], in clinical conditions is still considered ineffective in humans $[3,6,11]$. Moreover, disputes about using the specific electrostimulation algorithm are mostly caused by the lack of individual adjustment of parameters to the current functional state of muscles activity and nerve impulse transmission in iSCI patients. In most cases, standard, fixed programs with pre-determined parameters are delivered with electrostimulation equipment. However, most of them do not consider the objective results from precise, sensor-based neurophysiological tests performed prior to and after treatment, such as in the presented study. With the description of the standardized list of parameters necessary to define the algorithm of electrostimulation, such an approach would be promising due to the possible 
optimization of the parameters' safety. It would also allow the results to be compared, not only before and after treatment, but also between different studies. According to our research methodology and the results, the principles of electrotherapy algorithms were based on physiological premises, and software-supervised, personalized electrostimulation within nerve motor fibers enabled effective therapy for iSCI patients. Thus, it also helps to maintain nerve impulse transmission function in the period during which spontaneous repair phenomena are occurring at the level of the damaged spinal cord. We assume that the data from the stimulating device acting on the biofeedback rule motivated the subjects to obtain regular and continuous therapy, which was an important factor contributing to therapy effectiveness.

Few studies on the degeneration of motor fibers in the upper and lower extremities as a secondary change in the peripheral nervous system to spinal cord injury were reported. They provided evidence for abnormalities of the axonal type comparable to our study $[7,10]$. Lee et al. showed, similar to our research, evidence for the inhibition of degenerative changes in axons [15]. However, their analysis was performed for the short-term observation period following high-frequency $(100 \mathrm{~Hz})$, stimulation with $0.4 \mathrm{~ms}$ stimulation pulses and 5 times 30 -min sessions for one week. They did not provide the results of long-term observations. We used low-frequency stimulation, $39 \mathrm{~Hz}$ on average, and $17.5 \mathrm{~ms}$ pulses 5 times a week for $17 \mathrm{~min}$ sessions applied for 10 months, which, based on the methodological principles, seems safer because they were designed based on the current physiological and clinical status of the patients. We used a similar algorithm of electrostimulation to that recommended by Günter et al., who achieved positive effects after chronic stimulation at frequencies of about $30 \mathrm{~Hz}$ and percentages of effective stimulation time below $50 \%$ were considered as safe [6]. Nevertheless, they claimed that more precise data drawn from large databases are necessary.

Study participants were recruited between 4 and 12 months after injury. It is a well-known fact that, particularly in people with motor iSCI, substantial spontaneous neurological recovery occurs during this time [23]. The effectiveness of evidence-based motor rehabilitation methods, such as the presented electrotherapy, which support functional recovery in this period, should be further investigated and developed.

One of our study's limitations is that the mechanisms underlying stimulus-induced recovery are not well understood, which makes future research focused on the topic an essential source of data. Another is the heterogeneity of the spinal cord damage in iSCI patients assessed with the ASIA scale, although we attempted to recruit subjects with rigorous enrolment rules. The improvements found in the neurophysiological parameters in the cohort under investigation cannot be associated exclusively with the applied therapy. Different severities of incomplete spinal cord injuries, individual responses to treatment, a different spontaneous regeneration course, and the other unknown factors may affect the final result. Perhaps needle electromyography studies might provide convincing data on the motor neuron degeneration stage; however, this diagnostic method is invasive. In some cases, our patients with severe atrophic changes would further lose punctured myocytes. Thus, we decided also to use the non-invasive sEMG having in mind our patients' comfort and their well-being. In our study, we attempted to position the stimulating electrodes for electrotherapeutic purposes directly over the anatomical passage of peroneal and tibial nerves, considering the location of stimulating electrodes in electroneurographical tests prior to stimulation. We believe that thanks to such an approach, we avoided stimulation of surrounding excitable structures.

We are aware that having a non-treated identical control group (ideally submitted to a placebo-like intervention) in our study would broaden the scope of the functional regeneration mechanism from the view of basic neuroscience. On the other hand, it would be difficult for iSCI patients, who look for any improvement of their health status following applied electrostimulation, to understand the importance of the placebo approach in the project of which he or she should be informed in advance. Ethical and clinical responsibility does not allow for such a proposal for iSCI patients to verify our proposed therapeutic 
procedure with reference to the standard and the still limited available treatment methods. We believe that we cannot refuse the possibility of real electrotherapy treatment, the effectiveness of which was verified in the current study. The other limitation is the possibility that muscle fiber atrophy in iSCI patients might be partially caused by superimposing chronic immobility, which makes the interpretation of positive results of any treatment applied to iSCI patients difficult. We have studied patients in two groups with non-identical numbers ( 42 in the $\mathrm{K}+\mathrm{E}$ group versus 25 in the $\mathrm{K}$ group). However, it is unlikely that this kind of unbalance case data may influence the final results taking into account statistically significant therapeutical effects found in the $\mathrm{K}+\mathrm{E}$ group. We believe that the results of our study should be contrasted with 'in vivo' studies on animals, and histological verification should be performed to explain the degeneration and death of motorneurone phenomena.

\section{Conclusions}

This study demonstrates that axonal degeneration in motor fibers of lower extremity nerves, despite the absence of damage to lumbosacral neuromeres, is an inevitable secondary pathological change appearing after incomplete spinal cord injury at cervical or thoracic levels. This is likely to be caused by the lack of control from the supraspinal centers to the motoneurons below the level of damage. Pathologies in nerves make the recovery of the patient's motor abilities unattainable, even after spontaneous regeneration of spinal structures induced by intensive kinesiotherapy combined with electrotherapy. The individual algorithm of nerve electrostimulation applied in this study to the patients after iSCI, designed with the objective non-invasive neurophysiological tests, supported spinal cord regeneration. Such therapy may improve the neural transmission of nerve impulses, inhibit degenerative processes in axons, and accelerate axonal regeneration. Electrotherapy also enhances muscle contractile properties, thus diminishing pathological symptoms after iSCI. The specific neuromodulatory effect of FES may reflect the improvement in motor transmission not only peripherally but also at the interneuronal and motoneuronal levels. The importance of including electrotherapy in the current standard of care has been supported by the comparison of neurophysiological data in iSCI patients treated with kinesiotherapy (K group) and those treated with kinesiotherapy and electrotherapy ( $\mathrm{K}+$ E group).

We hypothesize that the improvement of motor function needed significant afferent input provided by the kinesioteherapeutic procedures applied to the patients of both groups. However, the electrotherapeutic stimulus transmitted via stimulated fibers might play a special facilitating role which influenced the effectiveness of treatment in the iSCI patients from the $\mathrm{K}+\mathrm{E}$ group.

The results of this study support the conclusion that FES may inhibit secondary degenerative changes in motor fibers, transmitting neural impulses from motoneurons to muscles in iSCI; thus, it may trigger their functional recovery. These findings contribute to the development of evidence-based therapies that promote recovery after spinal injuries.

Author Contributions: Conceptualization, J.H., A.W., A.S.-S., K.L., W.F. and P.T.; Investigation, J.H., A.W., W.F., S.O. and P.T.; Methodology, J.H., A.W., K.L., A.S.-S., W.F., S.O. and P.T.; Software, J.H., A.S.-S.; Validation, J.H., K.L., A.W., W.F., S.O. and P.T.; Formal analysis, J.H., K.L., A.W. and P.T.; Writing-original draft preparation, J.H., K.L. and A.W.; Writing-review and editing, J.H., K.L., A.W., W.F. and P.T.; Visualization, J.H. and K.L.; Supervision, J.H. and P.T. All authors have read and agreed to the published version of the manuscript.

Funding: This research received no external funding.

Institutional Review Board Statement: The study was conducted according to the guidelines of the Declaration of Helsinki and approved by the Bioethics Committee from the University of Medical Sciences (decision No 559/2018).

Informed Consent Statement: Informed consent was obtained from all the subjects involved in the study. 
Data Availability Statement: All the data generated or analyzed during this study are included in this published article.

Conflicts of Interest: The authors declare no conflict of interest.

\section{References}

1. Flynn, J.R.; Graham, B.A.; Galea, M.P.; Callister, R.J. The role of propriospinal interneurons in recovery from spinal cord injury. Neuropharmacology 2011, 60, 809-822. [CrossRef] [PubMed]

2. Leszczyńska, K.; Wincek, A.; Fortuna, W.; Huber, J.; Łukaszek, J.; Okurowski, S.; Chmielak, K.; Tabakow, P. Treatment of patients with cervical and upper thoracic incomplete spinal cord injury using repetitive transcranial magnetic stimulation. Int. J. Artif. Organs 2019, 43, 323-331. [CrossRef]

3. Nogajski, J.H.; Engel, S.; Kiernan, M.C. Focal and generalized peripheral nerve dysfunction in spinal cord-injured patients. J Clin. Neurophysiol. 2006, 23, 273-279. [CrossRef] [PubMed]

4. Kirshblum, S.; Lim, S.; Garstang, S.; Millis, S. Electrodiagnostic changes of the lower limbs in subjects with chronic complete cervical spinal cord injury. Arch. Phys. Med. Rehabil. 2001, 82, 604-607. [CrossRef] [PubMed]

5. Gordon, T.; Mao, J. Muscle atrophy and procedures for training after spinal cord injury. Phys. Ther. 1994, 74, 50-60. [CrossRef]

6. Günter, C.; Delbeke, J.; Ortiz-Catalan, M. Safety of long-term electrical peripheral nerve stimulation: A review of state of the art. J. Neuroeng. Rehabil. 2019, 16, 1-16. [CrossRef]

7. Asensio-Pinilla, E.; Udina, E.; Jaramillo, J.; Navarro, X. Electrical stimulation combined with exercise increase axonal regeneration after peripheral nerve injury. Exp. Neurol. 2009, 219, 258-265. [CrossRef] [PubMed]

8. Tabakow, P.; Jarmundowicz, W.; Czapiga, B.; Fortuna, W.; Międzybrodzki, R.; Czyż, M.; Huber, J.; Szarek, D.; Okurowski, S.; Szewczyk, P.; et al. Transplantation of autologous olfactory ensheathing cells in complete human spinal injury. Cell Transpl. 2013, 22, 1591-1612. [CrossRef] [PubMed]

9. Tabakow, P.; Raisman, G.; Fortuna, W.; Czyż, M.; Huber, J.; Li, D.; Szewczyk, P.; Okurowski, S.; Międzybrodzki, R.; Czapiga, B.; et al. Functional regeneration of supraspinal connections in a patient with transected spinal cord following transplantation of bulbar olfactory ensheathing cells with peripheral nerve bridging. Cell Transpl. 2014, 23, 1631-1655. [CrossRef]

10. Boland, R.A.; Bostock, H.; Kiernan, M.C. Plasticity of lower limb motor axons after cervical cord injury. Clin. Neurophysiol. 2009, 120, 204-209. [CrossRef]

11. Kern, H.; Carraro, U.; Adami, N.; Biral, D.; Hofer, C.; Forstner, C.; Mödlin, M.; Vogelauer, M.; Pond, A.; Boncompagni, S.; et al. Home-Based Functional electrical stimulation rescues permanently denervated muscles in paraplegic patients with complete lower motor neuron lesion. Neurorehabilit. Neural Repair. 2010, 24, 709-721. [CrossRef]

12. Chan, K.M.; Curran, M.W.T.; Gordon, T. The use of brief post-surgical low frequency electrical stimulation to enhance nerve regeneration in clinical practice. J. Physiol. Neurosci. 2016, 594, 3553-3559. [CrossRef]

13. Gordon, T. Electrical Stimulation to Enhance Axon Regeneration After Peripheral Nerve Injuries in Animal Models and Humans. Neurotherapeutics 2016, 13, 295-310. [CrossRef]

14. Carraro, U.; Kern, H.; Gava, P.; Hofer, C.; Loefler, S.; Gargiulo, P.; Edmunds, K.; Árnadóttir, I.D.; Zampieri, S.; Ravara, B.; et al. Recovery From Muscle Weakness by Exercise and FES: Lessons From Masters, Active or Sedentary Seniors and SCI Patients. Aging Clin. Exp. Res. 2017, 29, 579-590. [CrossRef]

15. Lee, M.; Kiernan, M.C.; Macefield, V.G.; Lee, B.B. Short-term peripheral nerve stimulation ameliorates axonal dysfunction after spinal cord injury. J. Neurophysiol. 2015, 113, 3209-3218. [CrossRef] [PubMed]

16. Willand, M.P.; Nguyen, M.A.; Borschel, G.H.; Gordon, T. Electrical Stimulation to Promote Peripheral Nerve Regeneration. Neurorehabil. Neural Repair. 2016, 30, 490-496. [CrossRef] [PubMed]

17. Lisinski, P.; Huber, J.; Samborski, W.; Witkowska, A. Neurophysiological assessment of the electrostimulation procedures used in stroke patients during rehabilitation. Int. J. Artif. Organs 2008, 31, 76-86. [CrossRef]

18. Wincek, A.; Huber, J.; Leszczyńska, K.; Fortuna, W.; Okurowski, S.; Chmielak, K.; Tabakow, P. The Long-Term Effect of Treatment Using the Transcranial Magnetic Stimulation rTMS in Patients after Incomplete Cervical or Thoracic Spinal Cord Injury. J. Clin. Med. 2021, 10, 2975. [CrossRef]

19. Huber, J.; Lisiński, P.; Polowczyk, A. Reinvestigation of the dysfunction in neck and shoulder girdle muscles as the reason of cervicogenic headache among office workers. Disabil. Rehabil. 2013, 35, 793-802. [CrossRef] [PubMed]

20. Wise, Y. Electrical Stimulation and Motor Recovery. Cell Transplant. 2015, 24, 429-446.

21. AuYong, N.; Lu, D.C. Neuromodulation of the Lumbar Spinal Locomotor Circuit. Neurosurg. Clin. N. Am. 2014, $25,15-23$. [CrossRef] [PubMed]

22. Jo, H.J.; Richardson, M.S.; Oudega, M.; Perez, M. The Potential of Corticospinal-Motoneuronal Plasticity for Recovery after Spinal Cord Injury. Curr. Phys. Med. Rehabil. Rep. 2020, 8, 293-298. [CrossRef] [PubMed]

23. Curt, A.; Schwab, M.E.; Dietz, V. Providing the clinical basis for new interventional therapies: Refined diagnosis and assessment of recovery after spinal cord injury. Spinal Cord 2004, 42, 1-6. [CrossRef] [PubMed] 